\title{
DE LA REFORMA URBANA A LA DEMOCRATIZACIÓN DE LOS GOBIERNOS LOCALES *
}

\author{
Alicia Ziccardi **
}

\section{PRESENTACIÓN}

Las grandes ciudades latinoamericanas han sido, y son en la actualidad, el espacio receptor de los procesos de modernización económica y social. Suele afirmarse que los rasgos más relevantes de las metrópolis latinoamericanas fueron su carácter primado y el ser el espacio de localización de la industria manufacturera que se desarrolló a partir de los cuarenta. Pero no menos importante fueron las profundas desigualdades que siempre existieron en el acceso a los bienes y servicios urbanos. Para algunos, nuestras ciudades ofrecieron buenas y hasta excelentes condiciones de vida, pero para muchos otros, nuestras ciudades fueron espacios donde sobrevivir supuso una penuria cotidiana. Hoy diríamos que se trató de una modernización excluyente ya que un amplio número de trabajadores urbanos debieron aceptar vivir en las grandes metrópolis soportando condiciones de vida precarias y deterioradas.

Estos procesos dieron lugar a la formulación de políticas urbanas implementadas por diferentes instituciones gubernamentales y también a la aparición de importantes movimientos sociales, cuyas principales demandas pasaron a ser la vivienda, los servicios y los equipamientos urbanos.

Diferentes proyectos modernizadores que se elaboraron, principalmente desde la gestión pública, se tradujeron en la creación de instituciones financieras y/o de asistencia social encargadas de atender estas demandas populares.

Este trabajo pretende presentar una revisión de un largo período en el que se transitó desde posiciones que sustentan la democratización de los gobiernos locales. Una última aclaración es que se hace especial referencia a México pero, en la medida de lo posible, se considera lo ocurrido en otros países latinoamericanos de mayor desarrollo económico y social, Brasil y Argentina.

\section{LA REFORMA URBANA: UTOPÍA DE DOS DÉCADAS}

Hace aproximadamente 20 años, cuando esta generación de urbanistas realizaba sus primeros trabajos de investigación sobre las ciudades latinoamericanas, uno de los temas de reflexión sobre las mismas era la reforma urbana. Las ciudades eran el principal escenario de las grandes desigualdades económicas y sociales que nuestras sociedades habían generado. Desde los sesenta, la marginalidad era un concepto que, elaborado desde diferentes perspectivas teóricas -funcionalistas y marxistas- servía para señalar la existencia, el comportamiento y las formas de organización social que desarrollaban los habitantes de las favelas, villas miserias, callampas, ranchos, y todas aquellas denominaciones que se les dio a los barrios populares constituidos por viviendas precarias, autoconstruidas por las clases populares, para sobrevivir en el medio urbano. Los conventillos, vecindades y cortiços eran la otra opción habitacional popular; una opción agotada ante la creciente demanda de vivienda de sectores pobres migrantes y los límites impuestos por la legislación a este tipo de oferta habitacional. La reforma urbana, al igual que la reforma agraria, era una alternativa ideológica formulada para alterar las formas de ocupación y usos del suelo en las ciudades latinoamericanas, pero con la finalidad última de acatar las desigualdades. El exitoso ensayo de Cuba, la propuesta parcial e incompleta en Bolivia y el frustrado proyecto de Colombia llamaban la atención de los urbanistas de la época ${ }^{1}$.

Lo fundamental es que la reforma urbana formó parte de la utopía de la ciudad enarbolada por los movimientos de pobladores autónomos, que se constituyeron en algunas grandes ciudades latinoamericanas (Buenos Aires, Río de Janeiro, Santiago) y que vieron frustrar sus expectativas con los sucesivos golpes militares que se dieron en estos países Brasil 1964, Argentina 1968, Chile $1973^{2}$.

Los investigadores de la época definían los alcances de esta propuesta de la siguiente manera:

Agradezco la colaboración de Lourdes Sánchez en las tareas de recopilación de información para la realización de este artículo.

** Investigadora del Instituto de Investigaciones Sociales de la UNAM y del Instituto de Investigaciones Sociales José María Luis Mora.

1. Véase Hardoy, Jorge y Oscar Moreno (1972).

2. Sobre el caso chileno existe una abundante bibliografía; véase. entre otros, Pastrana, Ernesto y Mónica Threfall (1974). sobre Buenos Aires Ziccardi, Alicia (1977) y una comparación sobre los movimientos de pobladores de Buenos Aires y Río de Janeiro puede hallarse en Ziccardi, Alicia (1983). 
Una reforma urbana suele ser confundida con un diferente sistema de administración de la tierra urbana y suburbana. Los que mantienen este enfoque aceptan que el Estado está en condiciones de suprimir la especulación, desarrollar servicios urbanos, incorporar tecnologías adecuada y facilitar el crédito sin modificar sustancialmente la estructura capitalista de la sociedad. Eso no es verdad. Para comenzar debemos otorgar a la reforma urbana alcances y objetivos más amplios.

No se trata, simplemente, de cambiar la relación legal que un individuo tiene con respecto a determinada superficie urbana. Se trata de un etapa política en un proceso que busca mejorar el funcionamiento económico del país y adecuar las ciudades a sus complejas funciones mediante una redistribución del poder político y de los recursos. Limitar una reforma urbana al control de la especulación de la tierra urbana y suburbana no significa necesariamente afectar a las grandes propiedades urbanas ni cambiar el sistema de tenencia de la tierra, ni reagrupar las tierras innecesariamente fragmentadas (Hardoy, Jorge y Oscar Moreno, 1972, p. 88).

Con cierta distancia respecto a las propuestas de los partidos políticos y/o de los movimientos de pobladores, los urbanistas interrogaban si el proceso de urbanización que presentaban las ciudades latinoamericanas constituían un freno al desarrollo, y de ser así, cuáles eran las políticas que debían adoptarse para modificar la estructura urbana.

Desideologizar el discurso e insertar la propuesta en el interior del conocimiento científico, era una tarea propia de los grupos intelectuales de la época. Desde esta perspectiva, las ciudades no eran un simple escenario de las grandes transformaciones o los centros más dinámicos de una sociedad. Las ciudades, su organización espacial, su infraestructura, sus equipamientos, su localización geográfica, su historia económica, eran componentes de la estructura y variables explicativas de procesos económicos, políticos y sociales más globales. Por ello, las propuestas de transformación de la estructura social no podían hacer caso omiso de la dimensión territorial -en este caso urbana-.

Pero más allá del debate teórico y de la utopía, diferentes instituciones e instrumentos fueron creados en los países de América Latina, con la finalidad de enfrentar uno de los efectos negativos de la industrialización: la pobreza urbana. No hubo más reforma urbana que la cubana, pero sí se crearon algunas instituciones gubernamentales con la intención de modificar las limitaciones de la estructura urbana y dar respuesta a los conflictos sociales generados por la demanda de bienes y servicios por los sectores populares; son bien conocidas las experiencias en materia de política habitacional de erradicación -término de la época- de los barrios pobres ${ }^{3}$. Fueron diferentes instancias de los gobiernos de las grandes ciudades - por ejemplo, la Municipalidad de Buenos Aires, el gobierno de Río de Janeiro- las que llevaron a cabo diferentes acciones y programas dirigidos a desalojar a la población de estos asentamientos populares; para ello se contó con la asesoría y/o recursos de organismos financieros internacionales y organizaciones de carácter asistencialista.

Con estas acciones se ponía fin, en esos países, a la utopía de lograr ciudades en las que el acceso a los bienes y servicios urbanos más elementales fuese más equitativo ${ }^{4}$.

Desde la perspectiva de las políticas públicas, si bien los primeros intentos de la planificación de las ciudades - planes reguladores- datan de los años treinta o aun antes en algunas capitales, la acción urbana gubernamental era fragmentada; esto fue así por lo menos hasta los años setenta. Es cierto que era una acción que disponía de recursos escasos para atender las grandes necesidades sociales existentes. Pero no puede decirse que fue la falta de instancias gubernamentales, de planes y programas y de urbanistas, lo que explica las formas y características que adquirieron nuestras ciudades. Fue el bajo nivel de ingreso de grandes sectores de la población, lo que limitó su acceso al mercado de bienes y servicios urbanos y las características de una política estatal limitada y no comprometida con proyectos de ciudades más homogéneas. El resultado fue la segregación social y territorial para las grandes mayorías; la conformación de varias ciudades en el interior de cada una, con los más variados niveles de habitabilidad pero en absoluta concordancia con los niveles de ingreso de cada sector social.

En México se creó, en 1976, una instancia del gobierno federal -la Secretaría de Asentamientos Humanos y Obras Públicas- encargada de atender la cuestión territorial a nivel nacional. Las ciudades pasaron a ser objeto de los miles de planes urbanos que se realizaron; sin embargo, es poco lo que este organismo logró incidir durante sus años de existencia en las políticas sectoriales y en los organismos ejecutores de la política urbana; menor ha sido su capacidad de legitimar la acción planificadora institucional y orientar la acción gubernamental efectivamente desplegada sobre el territorio nacional ${ }^{5}$.

En síntesis, los rasgos fundamentales de la acción gubernamental, los programas de las fuerzas políticas y la propia investigación urbano-regional en la época se caracterizaron por:

a) Considerar la ciudad latinoamericana de manera fragmentada y parcial privilegiando los problemas relacionados con las carencias -vivienda, servicios, transporte- de las clases populares y sin ofrecer una visión global e integrada -física, económica y sociopolítica- del espacio urbano en cuestión.

b) Algunas expresiones del regionalismo planificador se instalaron en los organismos estatales, pero no lograron ejercer una acción rectora ante los intensos procesos de urbanización y el comportamiento tradicional de las burocracias y de las élites gobernantes.

3. En Brasil el gobierno militar que derrocó a João Goulart creó el Banco Nacional de Habitação (BNH), la que entonces fue la más ambiciosa institución destinada a financiar vivienda popular.

4. En Buenos Aires, en los años sesenta, se programó la erradicación de villas miserias a cargo de la Municipalidad de Buenos Aires; durante el gobierno peronista de los setenta se formuló otro; finalmente fue la dictadura militar de esa década la que llevó a cabo un intenso proceso de expulsión de los villeros de la Capital Federal.

5. Entre otros véase Garza, Gustavo (1989), Ziccardi, Alicia (1991). 
c) La visión monolítica del Estado, reafirmada en el Cono Sur por la recurrente presencia de gobiernos militares, restaba visibilidad a los gobiernos locales; la acción de éstos en gran medida dependía de los recursos y lineamientos de política social del gobierno central.

\section{LA DESCENTRALIZACIÓN EN EL CONTEXTO DE LA CRISIS DE LOS OCHENTA}

Los ochenta se iniciaron con una grave crisis económica, producto del agotamiento de un estilo de desarrollo que llevó a los países del área a un creciente endeudamiento externo y a un incremento de los niveles de pobreza. El retorno a la democracia en Argentina y Chile y las exigencias de profundización de la misma en Brasil, México, Colombia y Perú abrieron nuevas expectativas en torno a disminuir las graves desigualdades económicas y sociales existentes.

Las grandes ciudades, las capitales en la mayoría de los países, eran las principales protagonistas de hechos políticos y demandas sociales. Constituían un colectivo, que más allá de sus diferenciaciones internas, adquirían protagonismo político y expresan las problemáticas que los estados debían incorporar en las agendas gubernamentales. La descentralización de los aparatos del gobierno federal y su contrapartida el fortalecimiento de los gobiernos locales, la revisión de competencias y facultades entre los diferentes niveles de gobierno, el traspaso de recursos a las instancias locales, fueron fórmulas que incorporaron las políticas públicas, a partir de la iniciativa de los gobiernos centrales.

En América Latina, es bien conocida la reforma municipal que se promueve en México en 1983, la cual traspasaba a estados y municipios facultades en materia de organización territorial, desarrollo urbano y suministro de servicios públicos (véase Martínez Assad y Alicia Ziccardi, 1989, Massolo, Alejandra, 1991). En este esquema de las reformas las grandes ciudades no fueron objeto de especial atención. En el caso de la ciudad de México la reforma legislativa sólo se aplicaba a los municipios conurbados del Estado de México.

Pero en la época existían propuestas que insistían en la necesidad de impulsar una reforma urbana en la gran capital y, a la vez, descentralizar recursos y poder para crear un gobierno local. Haciendo referencia a la ciudad de México se decía:

Si tantas agencias federales intervienen en las decisiones sobre la organización espacial de la ciudad no sorprende que la planificación y la otorgación de licencias resulte tan irregular, desigual y anárquica. La ciudad de México no tiene gobierno local. Lo que pasa por tal es un departamento administrativo encargado de ejercer y administrar las grandes inversiones determinadas por el ejecutivo...

La demanda de elección de regente no producirá cambios mientras se mantenga esta misma estructura desterritorializada de gobierno. Lo que debe exigirse es que haya un gobierno de la ciudad verdaderamente responsable de la organización material del marco urbano de nuestra vida cotidiana (Mori, Antonio, 1983, pp. 35).

La descentralización es un imperativo de los procesos de reestructuración de la organización territorial, pero también lo es para los proyectos más globales de reforma del Estado.

En México, la propuesta descentralizadora fue anterior a la adopción definitiva del modelo neoliberal, en el cual la reforma del Estado es estratégica. Esta no coincidencia de proyectos y tiempos, y fundamentalmente decisiones de orden político, impusieron fuertes límites a los proyectos descentralizadores. En general, en el contexto latinoamericano, los proyectos descentralizadores se han restringido al traspaso de algunas funciones y competencias de los gobiernos locales, presentando algunos rasgos comunes, tales como:

a) Instalarse más en el nivel del discurso que de la acción, sin lograr vencer las resistencias de las burocracias.

b) No superar la situación de debilidad y obsolescencia de los aparatos de gobierno local, los cuales continuaron subordinándose a la acción institucional federal.

c) Escasez de recursos de los ámbitos locales, lo cual es otro factor fundamental de esta subordinación.

d) No formulación de opciones descentralizadoras para las grandes ciudades, para las capitales de los países latinoamericanos

Respecto a este último señalamiento cabe afirmar que la descentralización y el fortalecimiento de los poderes locales fueron proyectos formulados y ejecutados como parte de una política destinada a contrarrestar la excesiva concentración metropolitana en una o unas pocas ciudades. Las ciudades medias pasaron a ser vistas como una opción territorial a la concentración y esto se tradujo en una política de apoyos y recursos para las mismas, las que se definieron sin criterios muy claros (véase Graizbord, Boris, 1991) ${ }^{6}$. Se trata de disminuir la población de las grandes ciudades o que no crecieran al ritmo que lo habían hecho en décadas anteriores. Pero no se introdujeron propuestas de descentralizar racionalmente las actividades y recursos concentrados en el espacio central, hacía su periferia territorial. Lo que ocurrió en las grandes ciudades fue el reforzamiento de los procesos de segregación social y espacial.

\section{EL ROL DE LAS GRANDES CIUDADES EN LOS NOVENTA}

Las transformaciones y/o los proyectos para las grandes ciudades en los noventa responden a los profundos cambios económicos y políticos por los que atraviesan nuestros países en este fin de siglo. Desde la perspectiva de

6. No existen criterios precisos para la definición de las llamadas ciudades medias. En México, se considera que existen alrededor de 80 ciudades que tienen entre 100.000 y un millón de habitantes y en las que vivían en 1990 alrededor del 25\% de la población del país. Cfr. SEDUE (1991) p. 66. 
la investigación urbana se debe prestar especial atención a las siguientes cuestiones, por las implicaciones especiales que las mismas tienen:

a) La reestructuración económica internacional ha llevado a que los países del área latinoamericana adopten las políticas de ajuste desdeñadas por el modelo neoliberal, como salida de la crisis de los ochenta. El lento crecimiento económico que muestran actualmente nuestras economías, se basa en los procesos de privatización y descentralización, el achicamiento de los aparatos del Estado con la consiguiente reducción de su burocracia, la apertura comercial hacia el exterior, la expansión de la sociedad informacional, las bajas remuneraciones a los asalariados y el crecimiento del trabajo informal, etc. Esta reestructuración económica exige una reestructuración territorial a nivel nacional, regional y local, en la que las grandes ciudades juegan un papel protagónico y estratégico.

Se afirma que el nuevo modelo conlleva la desterritorialización de las actividades económicas (Daniel Hiernaux, 1991) y es posible pensar que esto sea así a nivel internacional y en relación con el polo moderno. Pero en el caso de las ciudades latinoamericanas hay que investigar aún los efectos territoriales que provocan diferentes actividades que se instalan o expanden (maquila, informática, actividades del terciario moderno). También hay que dar cuenta de su contrapartida, el proceso de desindustrialización, que presentan las grandes ciudades.

En relación con el empleo urbano, los efectos de esta política son evidentes y se expresan en el abrumador crecimiento del trabajo informal en las calles de nuestras ciudades, lo cual genera múltiples consecuencias económicas, sociales y espaciales, sobre los usos del suelo. De igual forma, los niveles de ingreso cada vez más altos y concentrados llevan a la instalación de las cadenas internacionales de productos (alimenticios, del vestido, la electrónica y la informática) y la proliferación de centros comerciales, grandes espacios dedicados al consumo de élite, que bomogeneizan el espacio urbano, más allá de fronteras nacionales e identidades culturales.

b) Los límites de ese modelo económico se pueden medir a través de algunos indicadores de calidad de vida, los cuales señalan la magnitud de la extrema pobreza en que se hallan grandes sectores de la población. Esto ha llevado a que los mismos organismos internacionales recomienden la aplicación de políticas dirigidas a atender situaciones extremas. Las tradicionales políticas sociales de los estados latinoamericanos se están reformulando, y aunque es prematuro afirmar cuáles serán sus resultados en cada uno de los rubros que le competen (vivienda, salud, educación), es posible pensar que la tendencia es a disminuir el gasto público y el subsidio, así como a promover la privatización. Pero lo importante es que toda esta acción o inacción en materia de políticas sociales incide directamente en las condiciones de vida que prevalecen en las ciudades. Esto no es privativo de las ciudades latinoamericanas sino que los efectos negativos de este modelo sobre las ciudades y sus habitantes se advierten claramente en los países con mayor desarrollo. En algunas ciudades de Estados Unidos, por ejemplo Nueva York, la polarización y el dualismo social se expresan en una fuerte segregación espacial (Castells, Manuel, 1990); los estallidos de violencia recientemente vividos en varias ciudades norteamericana (en particular en Los Angeles) reflejan las implicaciones que tiene sobre la trama urbana, la exclusión económica y social de grandes sectores de población.

c) Desde una perspectiva política esta profunda reestructuración económica coincide con las demandas de la ciudadanía de consolidar y profundizar los procesos de democratización. Ello implica acercar la ciudadanía a los procesos de decisión, a las autoridades locales y a sus propios representantes; así como también permitir su acceso a diferentes instancias que formulan y realizan las políticas urbanas. La democratización de la gestión urbana es un requisito para modificar las marcadas desigualdades que existen en términos de acceso a la infraestructura y equipamientos, así como también para hallar soluciones a aquellos problemas que afectan al conjunto de la ciudadanía, por ejemplo la contaminación o el transporte.

Las grandes ciudades son actualmente el escenario de profundas transformaciones, son un colectivo social, que a pesar de sus diferenciaciones internas, presenta una nueva morfología social metropolitana (Martinotti, Guido 1990), que incide directamente en la sociedad. Es tarea de los urbanistas estudiarla, a fin de aportar conocimientos que puedan integrarse a las demandas más generales de democratización de la gestión urbana.

\section{LAS REFORMAS DE LAS GRANDES CIUDADES}

En varias grandes ciudades de América Latina, principalmente en sus capitales, con excepción de São Paulo, se están elaborando y realizando transformaciones en las estructuras político-administrativas de sus gobiernos. Estos procesos, más allá de enmarcarse en el contexto que hemos tratado de presentar sintéticamente en el punto anterior, poseen una dimensión territorial de la que deben ocuparse los urbanistas.

Las coordenadas de estos procesos desde la perspectiva territorial son dos: la metropolización y la descentralización. Ambos son procesos cualitativamente diferentes; el primero, instalado directamente en la esfera del urbanismo; el segundo, si bien pertenece también al mismo, es parte de una problemática más amplia: la reforma del Estado. A éstos puede agregarse un tercer eje de análisis, indisolublemente ligado a los anteriores: la institucionalidad, cuestión que no puede ignorar una propuesta de transformación de la ciudad.

\subsection{La metropolización}

Mundialmente, las ciudades, las metrópolis, han recobrado importancia en la formulación de las políticas públicas, particularmente con la idea del city márketing, en tanto estrategias tendientes a evidenciar las ventajas locacionales que ofrece determinada ciudad para desarrollar diferentes actividades. Esta imagen se ha impuesto sobre las imágenes de la crisis urbana que prevalecieron en la década anterior. 
El nuevo orden metropolitano se desvincula de los procesos de industrialización que fueron determinantes en el crecimiento de las ciudades, en un período anterior. Adquiere nuevas características y recurrencias entre las cuales destacan:

a) la conterurbanización -pérdida de población del espacio metropolitano central- hacia las periferias.

b) la transformación de la morfología física, social y administrativa de las ciudades, principalmente como consecuencia de los avances tecnológicos.

c) el debilitamiento de la identidad cultural de las ciudades en favor de su homogeneidad (Mc-Donalds en el paisaje urbano).

La política territorial en las metrópolis europeas se ha orientado hacia la denominada sutura de la ciudad, mejora en la calidad de vida de espacios urbanos individualizados, una vez detenida la expansión de la ciudad.Esta política refleja el pasaje de una preocupación cuantitativa, del crecimiento poblacional y la expansión urbana sostenida a la intención explícita de equiparar condiciones de vida para el conjunto de la ciudadanía.

El urbanismo se halla en una nueva etapa en la cual adquiere expresiones diferentes y contrastantes. Según Castells:

En Italia Aldo Rossi en su Arquitectura de la Ciudad, centró el esfuerzo del nuevo urbanismo progresista en un tratamiento formal de espacios simbólicos de la ciudad, recuperando las tesis esteticistas y monumentales del urbanismo, en una curiosa articulación entre el elitismo arquitectónico del pasado y el formalismo posmoderno del nuevo urbanismo progresista, unidos en su defensa de la vaporización del espacio como placer frente al instrumentalismo del desarrollo capitalista de la ciudad. En cambio, ninguno de los urbanistas españoles de primer nivel se interesó por replantear las formas y procesos de la ciudad, a partir de la extraordinaria revolución tecnológica vivida por el mundo en estos años (Castells, Manuel, 1990, p. 53).

Por otra parte, desde la perspectiva territorial -no sólo física sino económica y social- el concepto de gran ciudad tiene diferentes aceptaciones que deben distinguirse en la formulación de las reformas:

-La ciudad central que es el núcleo inicial y que muchas veces corresponde al municipio que lleva el nombre.

-La ciudad metropolitana que es la aglomeración constituida por la ciudad central y sus diferentes periferias.

-La ciudad-región que es el área real de planteamiento, de definición de las obras de infraestructura, de integración de la ciudad al territorio nacional ${ }^{7}$.

Cada una de ellas forma parte de un mismo territorio, de un continuo urbano, pero se distingue por las funciones y el papel que cumple cada subconjunto en esta heterogénea unidad.

Estas consideraciones en torno a la definición de la ciudad son fundamentales cuando queremos modificar sus formas de gestión haciéndolas democráticas y eficientes para mejorar la calidad de vida del conjunto de la ciudadanía.
El debate debe iniciarse preguntándonos sobre ¿cuál es la ciudad que queremos transformar? A cada una corresponde una realidad territorial y política específica para la que deben elaborarse propuestas diferenciadas. Sin embargo, el gran reto que actualmente tienen las grandes ciudades es el constituir (o mantener en su caso) un gobierno metropolitano democrático que realice una gestión eficiente en el suministro de los servicios públicos, en el cuidado del medio ambiente y en impulso que ofrezca al desarrollo de la economía local.

En este sentido, la principal propuesta urbanística para la gestión territorial de las ciudades en los países europeos es: la metrópoli policéntrica, en la cual se crean núcleos de actividad terciaria e industrial de alto nivel en la periferia y semi-periferia, a la vez que se otorga una nueva urbanidad, una mejora de la calidad de vida en los espacios centrales. Se trata de consolidar regiones metropolitanas policéntricas, en las que los distintos núcleos urbanos se conectan a través de grandes medios de transporte, se trabaja por lograr una mejor habitabilidad y medio ambiente y se intenta atraer continuamente actividades productivas. Es una concepción de aglomeración, no de fragmentación, la que prevalece y para ello en las grandes ciudades de varios países de Europa (España, Francia, Inglaterra) se ha creado un régimen especial de gobierno. Por ejemplo, en el caso de las grandes ciudades españolas se ha elaborado recientemente un proyecto de régimen especial, similar al Greater London Council (disuelto por el gobierno de la señora Margaret Thatcher). Sin embargo la estructura político-administrativa existente (comunidades autónomas, municipios periféricos) lleva a pensar que este gobierno metropolitano ideal no puede imponerse, por lo menos en Barcelona, ya que sería difícil vencer ahora un conjunto de obstáculos. Por ello, se ha propuesto una solución a dos niveles: a) el área metropolitana estricta, para la cual se propone la creación de un ente local, basado en la agrupación de municipios, para recibir transferencias de la Comunidad Autónoma y del Estado, encargado de atender principalmente lo relacionado con los equipamientos y servicios locales -cultura, vivienda, policía; b) la región metropolitana o área funcional, que es la ciudad-región, considerada el ámbito de la planeación territorial y de la gestión de algunos servicios públicos que sobrepasan el marco de la ciudad -transporte, agua y saneamiento, parques tecnológicos, etcétera. $\mathrm{Al}$ mismo tiempo, el proyecto prevé la creación de consorcios y otros organismos de concertación entre diferentes instancias. Lo importante aquí es considerar la diferenciación territorial y los alcances de las reformas que se proponen para cada espacio, en relación con las características que prevalecen en el momento de su formulación.

En América Latina, las anunciadas reformas de orden político-administrativo se dan en un momento en que el urbanismo parece estar en un impase. En México, luego de una experiencia de casi quince años de planeación territorial, fundamentalmente urbana e institucional, se producen

7. Sobre esto véase Borja, Jordi (1991). 
planes indicativos y marcos de referencia para acciones puntuales o programáticas, desarrolladas por alguna instancia de gobierno, encargada de tomar decisiones que tienen impacto territorial.

En algunas ciudades el urbanismo se subordina a la ejecución de grandes obras públicas, por ejemplo el metro, que no obstante atender demandas sentidas de los sectores de menores ingresos, no se integran necesariamente a una concepción de ciudad global.

La investigación urbana, por su parte, pocas aportaciones ha ofrecido; tal vez aquellos proyectos de reforma urbana encuentran hoy continuidad en un ideal similar que se expresa en una ciudad para todos. Pero prevalecen los enfoques parciales, que intentan captar una realidad urbana fragmentada en sus componentes -vivienda, transporte, servicios-, en la que la ciudadanía es una noción vaga y el énfasis está puesto en las tradicionales formas de relación clientelística entre autoridades y usuarios, en los logros y dificultades de los movimientos y actores sociales autónomos. Todas éstas son cuestiones socialmente relevantes, pero es necesario abordar los problemas de la ciudadanía y la complejidad de relaciones sociales que se viven en el contexto de la ciudad como un todo.

El modelo de ciudad, la ciudad que queremos, debe formularse previamente a cualquier proyecto de reforma. Ello implica confrontar imágenes e intereses -actores y conflictos- en ámbitos territoriales definidos (la ciudad central, las periferias, una delegación, una colonia, etc). Las reformas al gobierno de la ciudad de México, en la actual delimitación territorial, política y administrativa, se refieren al Distrito Federal (sus 16 delegaciones, su gobierno central, su Asamblea de Representantes). Para los municipios metropolitanos que pertenecen al Estado de México existe una legislación que fija competencias y funciones que rigen en materia de ordenamiento del territorio, el suministro de los principales servicios, la forma de constitución de los gobiernos municipales y sus relaciones con el estado (art. constitucional 115). En este sentido, los partidos políticos de la oposición -el Partido Acción Nacional (PAN) y el Partido de la Revolución Democrática (PRD)-, explicitaban, en sus plataformas electorales para 1991, propuestas relacionadas con la creación de instancias de gobierno de nivel metropolitano. El PAN recogía la experiencia de crear un régimen especial para la ciudad de México, tal como el que existe en algunas ciudades de Estados Unidos y Europa. Pero en estas propuestas no estaba claro aún cómo resolver las dificultades que surgen del diferente estatus jurídico-político de los municipios y las delegaciones.

Existen ya algunos mecanismos de coordinación metropolitana - por ejemplo Comisión Metropolitana de Transporte Urbano o la Comisión Metropolitana de Protección Ambiental-; en los años setenta y ochenta existieron la Comisiones de Conurbación -entre las cuales funcionó la de la región centro-. Todos estos instrumentos deberán ser evaluados en términos de su eficacia para incidir sobre las acciones gubernamentales a nivel metropolitano. También deberán incorporarse al debate reflexiones que permitan: a) Discernir las relaciones centro-periferia, a partir de una concepción policéntrica de la gran ciudad, definiendo espacios territoriales y político-administrativos precisos, según los objetivos y alcances de las propuestas.

b) Considerar los efectos diferenciales que, sobre el territorio y la sociedad, ejerce el nuevo modelo de crecimiento económico, en particular en la capital del país, y pensar a ésta como un espacio en transformación.

c) Evaluar las experiencias existentes en materia de instrumentos metropolitanos - por ejemplo el transporte-, así como las experiencias de planeación territorial -comisiones- que ya se han ensayado en la ciudad de México, a fin de pensar en propuestas cualitativamente superiores, en términos de gestión eficiente, de participación ciudadana, de racionalidad en la asignación de los recursos, etcétera.

\subsection{La descentralización}

La descentralización constituye la otra gran cuestión a introducir en un proyecto de reforma de gobierno local, en el que exista la intención de democratizar la gestión y promover la participación social.

Como ya se dijo, en América Latina la descentralización de los ochenta, se interesó poco por las metrópolis, aunque en algunas ciudades se registran experiencias de descentralización -por ejemplo Lima, Santiago- o existen actualmente proyectos que recuperan esta ideas de descentralizar la gestión urbana-Buenos Aires, México, São Paulo.

En Europa -Francia, Italia, España, Alemania- la descentralización fue una fórmula aplicada al conjunto del territorio, incluidas sus grandes ciudades.

En Francia, la descentralización contempló los 36.433 municipios de su territorio, 101 departamentos y 22 regiones; las ciudades de París, Lyon y Marsella fueron incluidas en la política del gobierno socialista. Algunas evaluaciones indican los efectos diferenciales que esta política tuvo sobre los municipios, sean éstos rurales, urbanos o parte de una gran ciudad, como las mencionadas. Para los primeros, la descentralización no tuvo grandes implicaciones. Para los segundos, la ley modificó la gestión del territorio al permitir que, a través de los mecanismos de proporcionalidad la oposición se incorporase al seno del gobierno municipal. Para las grandes ciudades se sancionó una ley especial, en 1982, según la cual se promovía la llamada descentralización inframunicipal que agregó, a las tradicionales figuras de los concejales y el alcalde, los llamados Consejos de distrito y diferentes formas de participación de los ciudadanos en las responsabilidades sociales (Laffanour, Anne, s/f).

En Italia, la descentralización urbana comenzó en los sesenta y setenta y el principio que la guiaba era la participación de los ciudadanos en la vida político-administrativa. La ley de reforma sobre las autonomías locales, de 1976, contemplaba 95 ciudades, en 56 de las cuales funcionaban organismos descentralizados; también en este caso se fijó la creación de consejos de distrito. Según se afirma, esta infradescentralización tenía un destino claramente abierto y dirigido a las grandes ciudades, pero no logró ser una descentralización efectiva, precisamente en el ámbito en que se 
lo propuso: la participación. Un trabajo que evalúa los alcances de la misma dice al respecto:

Por ejemplo, las comisiones circunscripcionales -compuestas por ciudadanos y expertos- se limitan a formular opiniones accesorias para el Consejo Comunal y la Asamblea (Merloni, Francesco y Grazia Vecchio, p.180).

Esto hace que, entre ciudadanos e instituciones, nuevamente, se reproduzcan relaciones formales y que sean los partidos políticos los que adquieran absoluta centralidad.

En América Latina, la descentralización fue vista como la posibilidad de que la gran ciudad, la ciudad primada -Buenos Aires o México-, disminuyera su peso económico y político, fortaleciendo para ello las ciudades medias y, en menor medida, los espacios locales -el municipio-. En México, se diseñó una política para más de 80 ciudades medias y se modificó la legislación relativa a las competencias y atribuciones de los estados y los municipios. La política de descentralización de los ochenta alcanzó ciertos logros y tuvo que enfrentar muchos obstáculos. Entre los logros suele incluirse el haber logrado incidir en la disminución de la población de la más importante zona metropolitana del del país: la ciudad de México. Pero las políticas urbanas, que habían comenzado a elaborarse desde mediados de los setenta, no fueron revisadas y/o actualizadas. Actualmente, no existen políticas urbanas explícitas para las grandes ciudades, no existen lineamientos precisos sobre su papel en la economía, las acciones gubernamentales no responden necesariamente a unas imágenes de ciudad a la que aspira la ciudadanía y las decisiones de inversión se deciden principalmente, en los organismos del gobierno federal.

La descentralización en América Latina, con las excepciones antes mencionadas, no concibió la infradescentralización como reestructuración de la gran ciudad. En todas hubo acciones sobre el territorio pero el urbanismo, como práctica profesional perdió espacio institucional.

Ahora, es necesario formular un modelo de ciudad, el cual no puede surgir de una práctica individual o grupal, es una tarea colectiva, es una tarea ciudadana, en la que deben participar necesariamente los urbanistas.

La descentralización sin duda es un proceso ineludible en la construcción de una ciudad distinta a la actual. En el caso de México deberá considerarse cuáles son sus alcances en los diferentes niveles territoriales existentes: 1) la ciudad central, cediendo recursos y poder de decisión del gobierno central a las 16 delegaciones; 2 ) la zona metropolitana traspasando poder del estado de México a los municipios metropolitanos -17 o 20 , según se los defina; 3) la ciudad-región trasladando o localizando nuevas actividades y creando la infraestructura productiva y de comunicaciones necesarias, en su territorio de influencia más amplio. Una aproximación a las plataformas de los principales partidos políticos, en 1991, indica que existe coincidencia en traspasar competencias y funciones que hoy ejerce el gobierno central a las delegaciones. Otro de los principales objetivos enunciados por las tres fuerzas partidarias es que la descentralización debe promover la participación vecinal, acercando autoridades y ciudadanía en los procesos de toma de decisiones. Sin embargo, si bien puede pensarse que en el mediano plazo se introduzcan reformas institucionales en el sentido de descentralizar la gestión hacia los territorios delegacionales, es más difícil pensar en un proceso de participación ciudadana autónomo; vencer la tradición clientelista, en sus más variadas modalidades, o modificar comportamientos fuertemente arraigados en las burocracias.

Por otra parte, las propuestas descentralizadoras, en cierto sentido son de signo opuesto a la metropolización; ésta última implica concebir la ciudad como aglomeración más que como unidades territoriales y administrativamente autónomas. Éste es uno de los dilemas que debe resolverse acertadamente, para lo cual considerar la temática de la institucionalidad es sumamente importante.

\subsection{La institucionalidad}

Otro conjunto de cuestiones ineludibles en las propuestas de reformas de los gobiernos de las ciudades, cuando se está pensando en modificar la gestión urbana son aquellas que forman parte de la llamada "ingeniería institucional" (véase, Jacobi, Pedro, 1991). Las reformas se dan en el interior de instituciones, instancias de gobierno, estructuras burocrático-administrativas, normativas y legales. Un proyecto de reforma, deberá contemplar cada una de las instituciones involucradas, las cuales tienen una dinámica propia y de conjunto, de acuerdo a los intereses y recursos que movilizan. Por ejemplo, en materia de política urbana, y con especial referencia al caso de México, es posible observar de qué manera, la normatividad en materia de vivienda y desarrollo urbano formulada por una agencia creada para ello (SAHOP) no fue asimilada por los organismos ejecutores de dichas políticas, con lo cual se produjo un claro divorcio entre planeación y acción urbana efectivamente realizada sobre el territorio; esto contribuyó finalmente a la disolución de esta instancia federal y a la actual incorporación de las principales funciones en la materia a una secretaría de muy reciente creación, cuya acción es más amplia: la Secretaría de Desarrollo Social.

Sonia Draibe pensando en torno a las reformas del Estado en los países latinoamericanos sostiene al respecto:

...En otras palabras, las reformas no se dan en medios vacíos, sino que ocurren en y son condicionadas por su medio específico -el institucional. En su formalidad, el medio institucional traduce a sus términos el proyecto de reforma, establece fuertes condicionantes para su temporalidad, e impone los contornos en los cuales se definirán y redefinirán todos los principios estructuradores del programa que se quiere reformar: desde su financiamiento hasta la prestación de servicios y los modos de control de su realización (1992, p. 10).

Estas observaciones llevan a enfatizar dos tipos de problemas fundamentales en cualquier proceso de reforma: 
1. El rediseño institucional de cada uno de los organismos o instituciones que participan directamente en la política urbana en cuestión.

2. El rediseño del contexto institucional más amplio, el que necesariamente está presente en la formulación y realización de esas políticas.

Éstas son cuestiones que los políticos, los investigadores y urbanistas deberán incorporar en el momento de diseñar las propuestas de reformas al gobierno de la ciudad, a las formas de gestión urbana. En este sentido, cabe recordar el ejemplo de Lima durante el gobierno de Izquierda Unida que tuvo que afrontar la inexperiencia administrativa buscando el apoyo de las organizaciones no gubernamentales (ONG'S) (Chirinos, Luis, 1991), o las dificultades del partido de los Trabajadores (PT) en São Paulo para conciliar las posiciones diferentes que surgen entre los administradores y los dirigentes, aun cuando ambos pertenecen al mismo partido político (Jacobi, Pedro, 1991).

Éstas son tan sólo algunas de las dimensiones que están presentes o subyacen en el debate sobre las reformas a los gobiernos de las grandes ciudades. Tal vez son las más importantes cuando se están pensando las reformas, desde la perspectiva de la gestión urbana, pero ello no excluye la consideración de otras dimensiones que también son de fundamental importancia, tales como: la económica, la financiera y fiscal, la partidaria, la relacionada con las formas específicas de participación social.

Para concluir, creo que es importante aclarar que este trabajo no sólo intenta sistematizar ideas para el debate actual sino que pretende presentar una síntesis de más de veinte años de experiencias de proyectos de reformas urbanas que, en sus diferentes expresiones y con poco éxito, propusieron ciudades distintas; ciudades en las que el conjunto de la población accediese a bienes y servicios básicos; ciudades que ofreciesen condiciones de vida dignas a todos sus ciudadanos. Pensar hoy en propuestas para mejorar la calidad de vida de la población, proteger el medio ambiente, crear formas de gobierno democráticas y eficientes, significa avanzar en esa misma dirección; por ello la experiencia y la memoria pueden aclarar y acortar el camino.

\section{BIBLIOGRAFÍA}

Ajuntament de Barcelona (1991). Régimen especial para las grandes ciudades. Barcelona.

Ayuntamientos de Madrid: Jornadas sobre las perspectivas de la descentralización -un análisis necesario-Madrid: mimeo, s/f.

BORJA, Jordi (1991). Un reto a la democracia: el gobierno de las áreas metropolitanas, mimeo, Barcelona

BorJa, J.; Castells, M.; Dorado, R. y Quintana, eds. (1990). Las grandes ciudades en la década de los noventa Editorial Sistema. Madrid.

BOUINOT, Jean. "La descentralización infra municipal en los países de Europa occidental”. en Ayuntamiento de Madrid, op. cit.

Camacho SOLIS, Manuel (1992). Comparecencia en Asamblea de Representantes del D.F., México 22 de abril.
CASTELls, Manuel. "Estrategias de desarrollo metropolitano en las grandes ciudades españolas: la articulación entre crecimiento económico y calidad de vida" en Borja, Jordi et al., op. cit, pp. 17/64

ChIRINOS, Luis. "El gobierno de la ciudad y el rol de las ONG: una aproximación desde el caso de Lima” en Ziccardi, Alicia (coord.). Ciudades y gobiernos locales en América Latina de los noventa. Instituto Mora, FLACSO y Porrúa. México, 1991

Draibe, Sonia M. (1992). A reforma do Estado na América Latina: observações sobre o caso brasileiro, mimeo, UNICAMP. Campinas, Brasil.

GARZA, Gustavo (compilador) (1989). Una década de planeación urbana en México (1978-1988). El Colegio de México, México.

GrAIZBORD, Boris (1991). "Estructura y dinámica de las ciudades industriales en el PNDU - 1984: posibilidades futuras de desarrollo". Ponencia presentada en el Primer Congreso de la Red Naciones de Investigación Urbana, México, octubre.

Hardoy, Jorge y Oscar Moreno (1972). "Primeros Pasos de la Reforma Urbana en América Latina”, en Revista EURE, vol. II, n. 4, Santiago de Chile, marzo, pp. 83 100.

JACOBI, Pedro (1991). "Gestión municipal y conflicto: el Municipio de São Paulo" en Ziccardi, Alicia (coord.) Ciudades y gobiernos locales en América Latina en los noventa. Instituto Mora. FLACSO y Porrúa, México.

LAFFANOUR, Anne. "Experiencias de descentralización en Francia”, en Ayuntamientos de Madrid, s/f, op.cit.

MARTínez AssaD, Carlos y Alicia ZiCCARDi (1989). "La descentralización de las políticas públicas en México” en Varios Autores. Centralización / descentralización del Estado y actores territoriales, CLACSO, Buenos Aires.

MARTINOTTI, Guido. "La población de la nueva morfología social metropolitana. Reflexiones a partir del caso italiano” en Borja, Jordi et al.,op.cit, pp. 65/139.

Massolo, Alejandra (1991). "Descentralización y reforma municipal: ¿fracaso anucuado y sorpresas inesperadas?", en Varios Autores Procesos rurales y urbanos en el México actual, UAM-I, México.

MERLONI, Francesco y Grazia Vecchio. "Descentralización administrativa, participación y gobierno de las áreas metropolitanas en Italia”, en Ayuntamiento de Madrid, op.cit.

MORI, Antonio (1982). "Ciudades: hacia una reforma urbana” en Nexos, núm. 50, México, febrero, pp. 31-35.

Partido Acción Nacional (1991). Plataforma electoral para el D.F., México.

Partido de la Revolución Democrática (1991). Plataforma electoral en D.F., México.

Partidos Revolucionario Institucional (1991). Plataforma electoral, D.F., México.

Pastrana, Ernesto y Mónica Threfall (1974). Pan, techo y poder. El movimiento de pobladores en Chile, Edición Buenos Aires.

PeASE Garcia, Henry (comp.) (1991). Construyendo un gobierno metropolitano políticas municipales 19841986, IPADEL. Lima. 
Secrataría de Desarrollo Urbano y Ecología (1990). Programa nacional de desarrollo urbano (1990-1994). México.

URRUTIA, Alonso y Víctor Ballinas (1982). "Hacia la democratización del Distrito Federal", El Perfil de la Jornada, México, 23 de marzo.

VAlladARes, Licia (1978). Passa-se uma casa. Zahar, Río de Janeiro.
ZICCARDI, Alicia (1983). "Villas miseria y favelas: sobre las relaciones entre las instituciones del Estado y la organización social en las democracias de los años sesenta" en Revista Mexicana de Sociología, año XLV, n. 1, IISUNAM, México, enero-marzo, pp. 45-67.

- (1991) Las obras públicas de la Ciudad de México (1976-1982), IISUNAM, México.

\section{RESUMEN}

Los problemas sociales que se manifiestan en la ciudad dieron lugar a la necesidad de planificar y gestionar las ciudades. Diferentes proyectos modernizadores tuvieron como base la democratización de los gobiernos locales, cuyo análisis es el objetivo de este artículo, con especial referencia al caso mexicano.

\section{ABSTRACT}

Social problems reflected in cities produce the need of urban planning. Different projects of modernization were based on local governments democratization. This is the object of this article, with special reference to mexican case. 